\title{
Beneath the umbrella: conservation out of the limelight
}

\author{
David W. Macdonald, Chris Newman, and Lauren A. Harrington
}

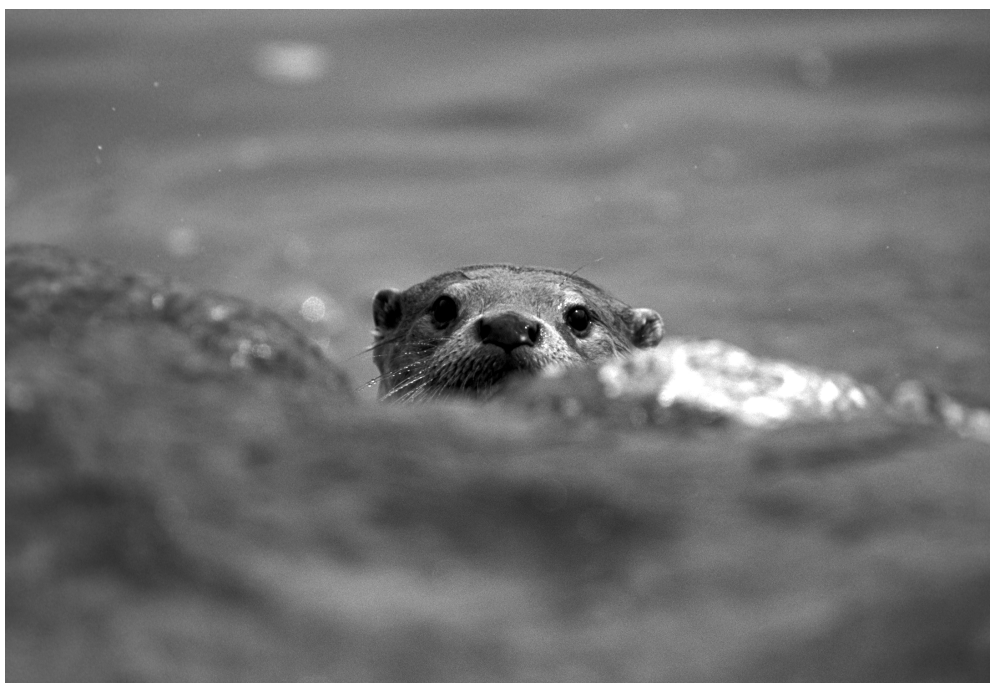

Eurasian otter (C) A.L. Harrington

Being special is not a prerequisite for meriting conservation, but nonetheless we begin by asking what is special about the musteloids in the context of promoting their conservation. To these ends, E. Macdonald et al. (submitted) identified two dimensions along which species, in this case mammalian species, can fruitfully be categorized: their charismatic appeal and their capacity to act as umbrellas for other, particularly other threatened, species. At the confluence of these measures, this approach has identified a category of mammals, termed 'ambassadors', which not only appeal strongly to survey participants but which also have a geographical distribution that overlaps more than average numbers of other species. Only $7.2 \%$ (312 of 4320) of terrestrial mammal species meet the stringent criteria of ambassadors. This classification combines potential to leverage public support for conservation with the species' capacity to encompass extensive or important geographical areas within its umbrella-its 'umbrella capacity', which reflects not only mammal community structure and biogeography, but also measures of evolutionary distinctiveness (ED) and endangerment. So, as one perspective on the question of what is special about the conservation of Musteloidea, we proceed by plotting them on this charisma versus umbrella capacity quadrant.

Macdonald et al.'s (submitted) approach grew from the observation that members of the Felidae were sympatric with threatened primates (Burnham et al. 2012), and that in many cases the threats they faced were similar; consequently there was a fair chance that they could all shelter under the shared umbrella of the same regional conservation interventions (Macdonald et al. 2012). The umbrella capacity of a species is calculated as the sum of the percentage of range overlap between the focal species and each of the other mammal 
species its range overlaps, multiplied by the EDGE score (a composite of ED and IUCN threat status, Isaac et al. 2007) of the overlapped mammal.

Meanwhile, mindful that while all species may be equal, some are more equal than others in the eyes of most people, E. Macdonald et al. (2015) demonstrated that in the opinion of at least the computer-literate and middle-class segment of the English-speaking public worldwide, carnivores in general, and large felids in particular, were regarded as particularly charismatic and, by extension, were valued as conservation priorities. The charisma dimension of Macdonald et al.'s (submitted) ambassadorial analysis took the declared preferences of 1536 survey participants (from five countries-the UK, USA, India, South Africa, and Australia) for 100 representative mammals, including six musteloids. Model averaging analysis revealed that preference scores for these 100 mammals were best described by body size (generally larger species are preferred), eye position, IUCN status, and threatto-humans. Using published data sets to obtain these data for all mammals, we could then use the preference values associated with each of these four attributes to calculate a charisma score for the remaining 4355 terrestrial mammals. We present the projected profiles of all musteloids in Figure 30.1, showing how they are distributed between the four quadrants of the charisma versus umbrella values.

Only five musteloid species (6.7\%) qualify as ambassadors according to the criteria of Macdonald et al. (submitted); that is, species with above-mean scores for both umbrella and charisma values. By contrast, $33 \%$ of felids, $5.7 \%$ of canids, and $13 \%$ of Carnivora overall qualify as ambassadors. Interestingly, all of the ambassadorial musteloids are mustelids, moreover all but one are otters (Eurasian otter [Lutra lutra] ranked

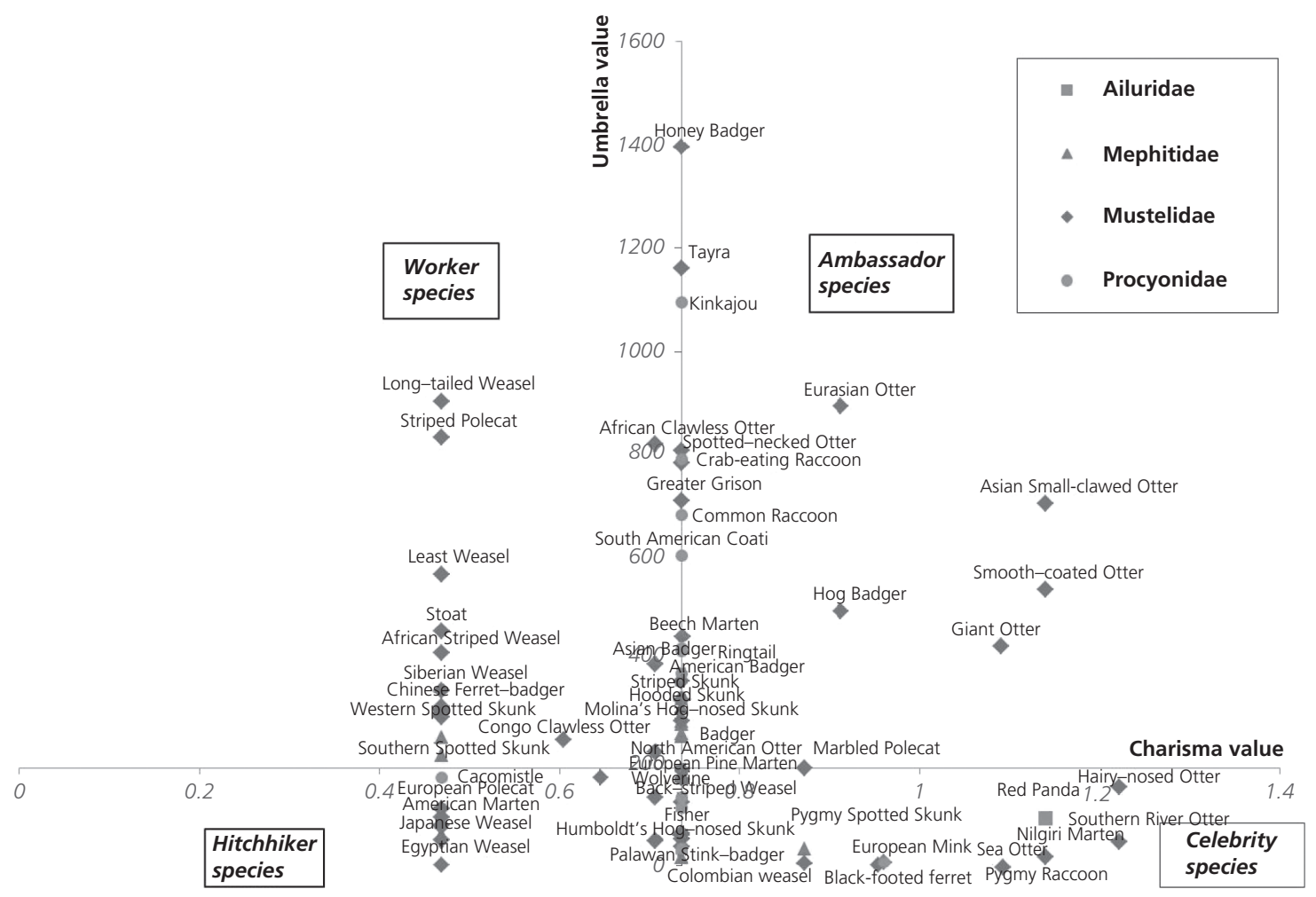

Figure 30.1 The distribution of all musteloid species across the four quadrants of the charisma versus umbrella plot. Charisma values are based on preference for large body size, forward-facing eye position, threatened IUCN status, and threat-to-humans. Umbrella values are a measure of the extent to which the ranges of other mammals are overlapped, weighted by the evolutionary distinctiveness and endangerment of the overlapped species. Axes are positioned at median values. See text for details; further explanation and details of calculations in E. Macdonald et al. (submitted). 
highest, Asian small-clawed otter [Aonyx cinereus], smooth-coated otter [Lutrogale perspicillata], and giant otter [Pteronura brasiliensis]; see Stevens et al. 2011) The other ambassadorial mustelid is the hog badger (Arctonyx collaris), which (when considered as a single species, as it was recognized by the IUCN Red List at the time of analysis, see Macdonald et al., Chapter 1, this volume) overlapped with nearly 600 other mammal species and, although not a conventional beauty, it derived much of its charisma score from the criterion of being relatively large bodied and through being classed as Near Threatened by the IUCN, whereas the majority (almost two-thirds) of musteloids are of Least Concern.

The Eurasian otter is the most ambassadorial of all musteloids, scoring well in both charisma and, in particular, umbrella score, overlapping with 1023 species-aided by its extensive transcontinental range. However, it still only ranked 18th in umbrella value and 62nd in charisma among the Carnivora as a whole.

With regard to pure charisma, the hairy-nosed otter (Lutra sumatrana) and the southern river otter (Lontra provocax) lead the field, whereas in terms of umbrella value, the honey badger (Mellivora capensis), tayra (Eira barbara), and kinkajou (Potos flavus) trump any definitive ambassador, due to their range overlap with a diversity of other threatened mammals.

The best umbrella species amongst the procyonids is the kinkajou. But, whilst it is hugely popular amongst animal-lovers (Brooks and Kays, Chapter 26, this volume; Harrington et al., Chapter 7, this volume), it has only an intermediate charisma value as a species of conservation priority because it is classed as Least Concern by IUCN and has an intermediate body size compared to the rest of Mammalia. Combined with its umbrella value, this keeps it only on the edge of ambassador status. The most charismatic procyonid is the Cozumel or pygmy raccoon (Procyon pygmaeus; charisma, in this case, largely driven by its Critically Endangered status), but its restricted island distribution translates into a low umbrella score, leaving it in the 'celebrity' rather than 'ambassador' quadrant (meaning it has high charisma but a low umbrella value). Similarly, the Endangered red panda (Ailurus fulgens) is high in charisma but low in umbrella value, also rendering it a 'celebrity' species.

Despite their attractively strident appearance (although 'charisma' did not take body markings or odour into account), skunks (mephitids) perform poorly: only the pygmy spotted skunk (Spilogale pygmaea) scored above average in charisma value due to being classed Vulnerable by IUCN, but its low umbrella score rendered it only a weak 'celebrity'. The other skunks were categorized in the 'worker' quadrant (low charisma but high umbrella value). Sea otters (Enhydra lutris) and black-footed ferrets (Mustela nigripes), like the red panda (and the lesser-known pygmy raccoon) are notable as celebrities thanks to their considerable charisma (driven by their Endangered statuses, see Estes et al., Chapter 23, this volume; Biggins and Eads, Chapter 15, this volume) and notwithstanding their rather modest umbrella ranking (226th and 228th of the Carnivora) arising from very restricted current ranges.

Most other mustelids are categorised as workers (whilst ranking variously well as umbrellas, they score poorly on charisma) and a large proportion fall in the quadrant with least conservation influence, the hitchhikers (with both charisma and umbrella scores below par, Figure 30.1). The Egyptian weasel (Mustela subpalmata; a human commensal restricted to urban habitats in Egypt) has the unfortunate distinction of being the weakest candidate for marketing conservation in this scheme.

The distribution of musteloids between the four quadrants differ significantly from mammals as a whole $\left(\chi^{2}=24.00, \mathrm{df}=3, \mathrm{p}<0.001\right)$ and the Carnivora as a whole $\left(\chi^{2}=8.94, \mathrm{df}=3, \mathrm{p}=0.030\right)$, with just $6.7 \%$ of musteloids qualifying as ambassadors $(5 / 75$ of those for which E. Macdonald et al. [submitted] calculated both umbrella and charisma scores), while $14.7 \%$ $(11 / 75)$ are celebrities, $50.7 \%(38 / 75)$ are workmen, and $28 \%(21 / 75)$ are hitchhikers (see Figure 30.1). As a result, musteloids, except for the high-scoring lutrines, generally present only modest candidates as ambassadors, scoring marginally higher than canids but substantially lower than felids from the perspective of conservation marketing. This book is the third of a trilogy, focussing successively on the biology and conservation of canids, felids, and now musteloids, and so Figure 30.2 compares the distributions of the former two families with this superfamily.

Considering the corollaries of charisma identified by E. Macdonald et al. (2015), the major deficiency of the musteloids in the theatre of public acclaim is their relatively small size - the very same characteristic associated with their successful roots as rodent hunters in the Oligocene grasslands (Macdonald and Newman, Chapter 6, this volume). Of course, the generalities identified by Macdonald et al. (submitted) are just that: generalities, from which there will be exceptions. The black-footed ferret provides a well-known 


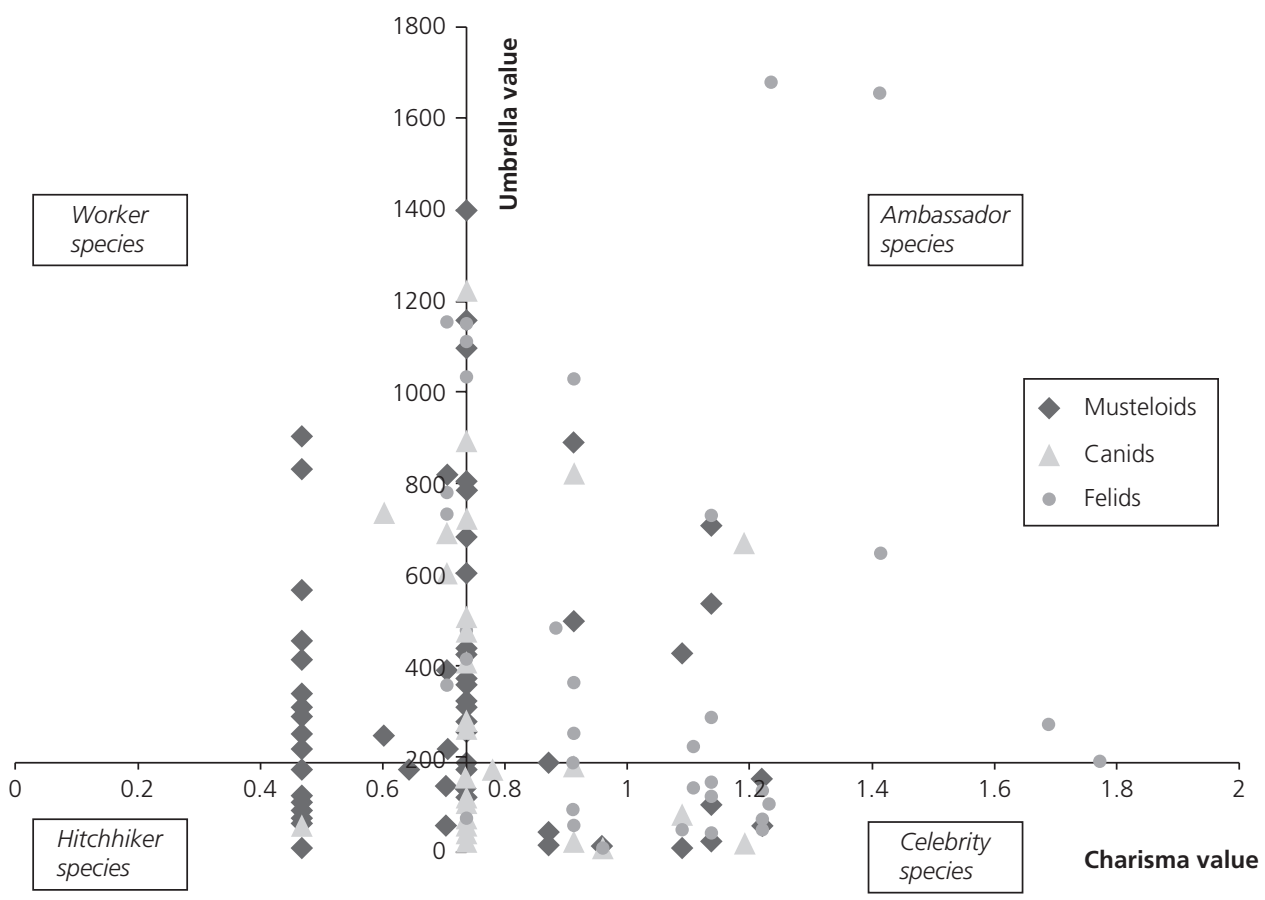

Figure 30.2 The distributions of felid and canid families with the Musteloid superfamily across the four quadrants of the charisma versus umbrella plot. (See text and Figure 30.1).

case of an internationally famous mustelid conservation story (Biggins and Eads, Chapter 15, this volume) and the European badger (Meles meles) is equally well known, although controversially so (Woodroffe and Donnelly, Chapter 20, this volume). Similarly, otters have great public appeal. But, given that most musteloids are relatively unpromising in the role of flagships for conservation, we turn to the more ecological question of what ecosystem services they provide.

\section{What ecosystem value do the musteloids bring?}

Moving to ecological roles and functions, would we notice the demise of musteloids? There is increasing recognition that removing large predators can trigger ecological cascades. Specifically, Ripple et al. (2014) highlight a series of Ecosystem Services (e.g. Balvanera et al. 2006) that carnivores can provide, and we next explore if and how musteloids contribute to these. There are many criteria across which a species might contribute to ecosystem processes, but for focus, and to integrate a sense of the utility value we place on these processes, here we use the framework encapsulated by the Millennium Ecosystem Assessment's definitions of cultural, provisioning, supporting, and regulating services (Millennium Ecosystem Assessment 2005).

\section{Cultural services-ecotourism and recreational value}

Because of their diversity and near global distribution, musteloids occur in many protected sites throughout the world, but they generally solicit less specific interest from tourists than big, rare carnivores. There are, however, a few exceptions: for example, eco-tourist agencies in Mexico and Belize frequently list kinkajous and cacomistles (Bassariscus sumichrasti) as visitor attractions, and the red panda is often used to market tours to Nepal, Bhutan, and China. The Earthwatch Institute (a Citizen Science organization, detailed by Buesching et al. 2015) lists kinkajous and coatis (Nasua spp.) to attract citizen scientist participation in their Costa Rican study. Sea otters are star attractions in the Monterey Bay National Marine Reserve and Aquarium in California, and boat tours relay hordes of visitors to watch them 
off the coast of British Columbia (Canada) and Alaska. Indeed, although sea otters can compete with fishermen for shellfish, Loomis (2006) demonstrated that on the Santa Barbara coast the economic benefits of sea otter expansion exceeded the costs to commercial fishing. Riverine otters can also attract tourist interest; for instance, otter watching attracts visitors to Scottish lochs. Amulike et al. (2013) have conducted research to assess the potential for spotted-necked otters (Lutra maculicollis) to serve as flagship species at Rubondo Island National Park, in Tanzania.

Despite the current opprobrium with the UK farming community (Woodroffe and Donnelly, Chapter 20, this volume), European badgers remain popular among nature lovers, and have iconic status as the logo for the UK's Wildlife Trusts (www.wildlifetrusts.org). The hobby of badger-watching is popular, and the UK's Badger Trust (www.badger.org.uk) has over 3000 members. Indeed, Woodroffe and Donnelly report how badger culling is in the top five issues about which UK Members of Parliament receive letters from constituents, ahead of more apparently mainstream topics such as education, social security, and taxation (IpsosMORI 2014).

\section{Provisioning services-hunting as a source of food, skins, and trophies}

Over 50 of the musteloids worldwide, and all North American musteloids (sea otters only by indigenous people), are harvested as furbearers (Harrington et al., Chapter 7 , this volume), making them a very popular group with recreational, commercial, and subsistence hunters and trappers. The American mink (Neovison vison) is undoubtedly the most significant commercial furbearer among the Carnivora, globally, but to satisfy demand for mink pelts, most are farmedapproximately 50 million farmed mink pelts were offered for sale in 2016 via the two major European auction houses (Kopenhagen Fur in Denmark and Saga Furs in Finland), compared with approximately 100,000 wild mink pelts harvested annually in the US.

As Sam Zeveloff describes in Chapter 27, raccoons (Procyon lotor) are the species most exploited for their pelts in North America, despite these pelts being of relatively low value. Crucially, from a conservation management perspective, North American estimates of raccoon population abundance are based entirely on total annual harvest bags, the intention being broadly to maintain a population able to sustain this exploitation (e.g. Taylor and Dunstone 1996).
A similar situation exists for other North American musteloid furbearers, such as striped skunk (Mephitis mephitis), wild mink, otter, marten (Martes americana), fisher (Pekania pennanti), and wolverine (Gulo gulo). Thus, although (for some species) interactive with measures to control the spread of rabies (see below; Newman and Byrne, Chapter 9, this volume), these 'commodity musteloids' have commercial value. Increasingly, however, this trapping is recreational and, even when sustainable, attracts criticism from those who take an ethical stance against hunting (e.g. in a related context, Macdonald et al. 2016a; see also Harrington et al., Chapter 7, this volume).

Not as well known, nor as sought after, by international trophy hunters, as the 'Big 5' (lion, elephant, white rhino, leopard, buffalo), CITES nevertheless records (www.cites.org) increasing numbers of honey badger 'trophies', skins, and other body parts exported from African range states (predominantly to the US and Japan, Harrington et al., Chapter 7, this volume).

Mustelids have rarely been eaten in the western world, but, as Youbing Zhou and colleagues describe in Chapter 13, even today, in China, hog badgers are consumed in rural communities. Indeed, Chen et al. (2015) argue that this exploitation is unsustainable in Hubei Province and threatens regional populations, as well as causing welfare concerns. In Chapter 7 (this volume) Harrington et al. report that, globally, over 20 musteloid species are hunted for food at least occasionally.

\section{Supporting services-predating the consumers of primary productivity}

Ripple et al. (2014) describe how large, often iconic, predators can become imperilled because they have high demands for (usually large) prey; prey that can include livestock and even occasionally people. But carnivores play key ecosystem roles; by limiting herbivore prey numbers they can reduce habitat degradation through grazing and browsing (Noy-Meir 1975), encourage forest regeneration (Ripple et al. 2010), and arguably facilitate pastoral grazing of livestock (Wallach et al. 2015). But do comparable ecosystem services accrue from small predators?

Small specialist predatory mustelids have a particular effect on their rodent prey. Whereas larger rodent predators (foxes, small felids, etc.) are more generalist and switch prey when rodents become scarce, Mustela species continue to hunt mice, voles, and lemmings down to very low numbers, even under snow 
in winter, when other predators can struggle to hunt rodent prey and often turn to alternative food types. As Xavier Lambin explains in Chapter 4, this can sometimes cause rodent populations to cycle inter-annually with dramatic amplitude, especially in high-latitude regions where mustelids are the dominant predator group. However, because these Mustela spp. are themselves small enough to fit into prey-size range taken by owls, raptors, and other larger terrestrial carnivores, lateral intraguild predatory links can dampen trophic cascades. As a result, the effect of small mustelid predation varies between ecosystems.

So what if there were no weasels-what would the implications for rodent populations and cascade effects be? Korpimäki and Norrdahl (1998) reduced the densities of small mustelids (least weasel [Mustela nivalis] and stoat [Mustela erminea]) along with avian predators (Eurasian kestrel [Falco tinnunculus] and Tengmalm's owl [Aegolius funereus]) of the field vole (Microtus agrestis) and bank vole (Myodes glareolus) over six replicated $2-3 \mathrm{~km}^{2}$ areas in western Finland. Over two crash phases (1992 and 1995), reducing all predators lessened the summer decline in rodent densities (whereas rodent densities crashed in control sites) but controlling weasels alone was not sufficient to have an impact, although weasels consumed up to $40 \%$ of rodent prey in the region.

In Bialowieza National Park, Eastern Poland, using census data from 1985 to 1992, Jędrzejewski et al. (1995) found that, during rodent population cycles, the numbers of weasels and rodents (both sampled at 2-3 month intervals) correlated positively, with no time lag. Over the seven autumn-winter seasons studied, weasels consumed, on average, 1.6 to 9.5 rodents per hectare (approximately $2 \%$ to $28 \%$ of this prey population). Winter predation by weasels was heaviest at rodent densities of $c .20$ individuals per ha. At lower rodent densities, the role of weasel predation was much smaller, restricted by food shortage. Although the annual increase in weasel numbers from spring to mid-summer was positively related to the spring density of rodents, the autumn and winter decline of weasel numbers was not.

In Kielder forest, Northern England, Graham and Lambin (2002) also reduced weasel densities through live trapping and removal, and found this accounted for $c .26 \%$ annual survival rate benefit for field voles. Surprisingly, weasel removal reduced juvenile field vole survival, possibly reflecting increased emigration or mortality due to infanticide. They concluded that the impact of weasel predation on field vole survival was neither sufficient nor necessary to initiate and drive the cyclic decline of field vole populations at this site (see Lambin, Chapter 4, this volume). This substantially contradicts the proposition that mustelids might fundamentally limit rodent population density (see Oli 2003), and so rather than small mustelids controlling prey numbers, it seems that prey regulates mustelid abundance.

What of bottom-up cascades? Primary productivity, such as tree mast crops (e.g. seeds of oak, hornbeam, and maple), are often fundamental to rodent population success (Wolff 1996); and so to the extent that prey regulate predator density cycles, a bad mast crop year can deplete mustelid populations (Ostfeld and Keesing 2000). Effects can also be interactive; Dunn (1977) found that weasel predation pressure on tit species (Parus spp.) in Wytham Woods, England, was alleviated by higher rodent availability but exacerbated in years with lower rodent abundance.

Musteloids feeding on rapidly renewing invertebrate prey seem unlikely to exert a major limiting force. For instance, badgers have no enduring impact on their earthworm prey (Newman et al., Chapter 21, this volume). Similarly, skunks will only make localized impressions on available invertebrates (Greenwood et al. 1999).

What about predators of fish-the otters? Although many anglers perceive otters as competition, when otter numbers in the UK were severely depressed through the 1950s-1980s (Mason and Macdonald 2009), largely due to organochloride pesticide poisoning arising through bio-accumulation in river systems (Yamaguchi et al. 2003b), riverine fish stocks did not explode. There was, however, a trend towards increasing size and dominance of specimen fish species such as chub (Leuciscus cephalus) and barbell (Barbus barbus)_favoured by fishermen in the short-term, but potentially associated with poor recruitment, skewed age structure, and subsequent senility of fish populations (Crawford 2010).

Two well-investigated predatory roles do stand out amongst the musteloids. As Jim Estes and colleagues explain in Chapter 23, sea otters control populations of herbivorous marine macro-invertebrates, particularly sea urchins (Strongylocentrotus franciscanus), as well as gastropods, bivalves, and crustaceans. Consequently, any local demise in sea otters (frequently driven by disease epizootics; see Newman and Byrne, Chapter 9, this volume) releases these invertebrates 
from predator regulation, resulting in massive grazing impacts on marine macrophytes, mainly kelps. By this same token, the re-establishment of sea otters indirectly impacts the entire trophic web; thus, in a roundabout way, sea otters prove important in restoring kelp beds (Estes and Palmisano 1974); as has happened in islands in the Aleutian archipelago (Reed and Brzezinski 2009). Kelp forests have substantial net primary productivity and so effects ramify through the food chain.

The second keystone effect of musteloids involves the role of frugivorous species in seed dispersal, with only bears rivalling this trophic eclecticism. Working with Youbing Zhou, we have established that yellowthroated martens (Martes flavigula, Zhou et al. 2008a, 2011a), and Chinese ferret-badgers (Melogale moschata, Zhou et al. 2008b) contribute significantly to the guild of seed dispersers in subtropical forests in central China. For example, when an unprecedented winter storm struck the research area (Houhe National Nature Reserve) in 2008, although trees continued to fruit, these martens and ferret badgers switched from fruit to consume more protein-rich mammals and birds. As a result, the dispersal function of many trees, but especially the raisin tree (Hovenia dulcis), was decimated and took over two years to recover (Zhou et al. 2013b). In the Neotropics, kinkajous (Brooks and Kays, Chapter 26 , this volume), and potentially many of the other procyonids (Macdonald et al., Chapter 1, this volume), play a similar frugivorous role and thus make a substantial contribution to seed dispersal (JulienLaferrière 2001).

\section{Regulating services-carbon sequestration and disease control}

Predators can influence the exchange of $\mathrm{CO}_{2}$ between ecosystems and the atmosphere by altering ecosystem processes such as decomposition and primary production. Furthermore, predators in odd-numbered freshwater food chains tend to suppress $\mathrm{CO}_{2}$ emissions, while predators in even-numbered food chains enhance emissions (Wardle et al. 2005).

Returning to sea otters, Wilmers et al. (2012) estimate that when they limit kelp grazing, an additional 4.4 to 8.7 teragrams of carbon remains stored, valued at c.USD 205 million to 408 million on the European Climate Exchange. In freshwater ecosystems other otters and mink (feeding on muskrat [Ondatra zibethicus]; see Lambin et al., Chapter 4, this volume) also have potential to affect carbon sequestration by predating primary consumers. Indeed, Atwood et al. (2013) report that in freshwater ecosystems the removal of predators caused a tenfold rise in $\mathrm{CO}_{2}$ emissions. This phenomenon has been less thoroughly investigated in terrestrial ecosystems, but despite each individual rodent consuming only a tiny volume of vegetation per day, rodent numbers can be substantial across regions. Consequently, predation on rodents likely preserves stored carbon in plants (Fan et al. 2003).

It is not just the role of musteloids as predators in uneven food chains that can affect carbon, and thus climate; sometimes they themselves are the primary consumer. Badgers consume earthworms (Macdonald et al. 2015b) and earthworm activity affects how much $\mathrm{CO}_{2}$ (and nitrous oxide) is sequestrated and mineralized into the soil, via earth worm digestion and how much escapes to the atmosphere (Lubbers et al. 2013; Zhang et al. 2013) -in turn products of the timescale over which any assessment is made.

The availability of earthworms to hungry badgers is determined by surface soil cover and micro-climate (Newman et al., Chapter 21, this volume). For our focal high-density ( $>40$ badgers per $\mathrm{km}^{2}$ ) badger population at Wytham Woods (Oxford; see Macdonald et al. 2015 b) we estimate that each badger consumes around 100 earthworms (2000 kJ) per good 'worm-night'. This amounts to around $200 \mathrm{~kg}$ of earthworms per hectare per year, over the 600 ha population range. We are yet to model the full implications on $\mathrm{CO}_{2}$ dynamics, but we predict a critical link to energy (carbon) and other nutrient cycle (e.g. nitrogen) chains. These data will inform views on badger culling (Woodroffe and Donnelly, Chapter 20, this volume), which might inadvertently cause biogeochemical cascades with potential to affect climate change. Of course, skunks, raccoons, coatis, and other Old World badgers (Zhou et al., Chapter 13, this volume) also eat substantial quantities of invertebrates with similar potential to affect carbon storage.

Predators can also play a crucial pest and pathogen control service, through the top-down regulation of disease-spreading prey. Ostfeld and Holt (2004) evidence a positive effect of predators on reducing zoonotic epidemics (e.g. Packer et al. 2003) and many musteloids predate disease-spreading rodents (Meerburg et al. 2009). Notably, however, as Dean Biggins and David Eads discuss in Chapter 15, already decimated black-footed ferret populations eating prairie dogs infected with sylvatic plague actually contracted 
the bacterium themselves, and were almost wiped out. Similarly, badgers consuming rodents infected with the protozoan Toxoplasma gondii can acquire the disease directly (Anwar et al. 2006; Newman and Byrne, Chapter 9, this volume).

Thus far, we have focussed on factors promoting the case for musteloid conservation. Unfortunately, this case becomes harder to advocate for species with a reputation for causing conflicts with our other interests (e.g. Treves and Karanth 2003; reviewed for musteloids in Harrington et al., Chapter 7, this volume). For instance, most people know skunks primarily because of their defensive ability to spray noxious anal gland defences (Buesching and Stankowich, Chapter 5, this volume), and they encounter raccoons predominantly as garbage can raiders or crop thieves; further fearing these species because of their role in rabies zoonoses (Newman and Byrne, Chapter 9, this volume). Similarly, in the UK, the European badger is 'infamous' due to its role in bovine tuberculosis epizootiology (Woodroffe and Donnelly, Chapter 20, this volume). These traits create resistance to conservation, so next we briefly exemplify some of the problematic conservation issues musteloids can pose.

\section{Conflicts-circumstances necessitating 'conservation management'}

While we see some evidence for musteloids regulating prey, this predation, from a human perspective, becomes undesirable (and thus requires intervention) when it affects economic interests. Indeed, the primary reason small Mustela spp. are persecuted is to protect poultry and wild gamebird stocks; although in the grand scheme, trapping and killing mustelids is often ineffective, and the cost involved versus the financial benefit usually proves uneconomic. Inevitably, attempts have been made to put the lethality of small mustelids to work, to control unwanted rodent densities. But, even in their native ranges, this approach has proven unsatisfactory (Wodzicki 1973). Worse, in situations where Mustela spp. have been introduced, such as New Zealand, devastating unintended consequences for native fauna have ensued (King et al., Chapter 10, this volume).

A similar situation afflicts aquatic mustelids, where recent recoveries amongst Eurasian otter populations, due to better environmental practice and otter protection, are increasingly causing problems for fish-stock management, particularly in the pond fisheries of Central and Eastern Europe (e.g. Adámek et al. 2003;
Kloskowski 2005, 2011). Recovering sea otter populations are probably incompatible with commercial abalone fisheries, which were established in their former absence (Fanshawe et al. 2003). Other otter species elsewhere in the world are also perceived to take fish that would otherwise be available for people to eat, although, in many cases, overlap in fish species consumed by otters and people is rather low (Harrington et al., Chapter 7, this volume, and references therein). Nevertheless, in many parts of the world, threatened otter species are persecuted to reduce fish predation, and even in Europe, Eurasian otters are occasionally shot illegally.

What about bigger musteloid predators? More in line with conflicts involving large canid and felid predators, wolverines take lambs (Landa et al. 1999) and domestic reindeer (Andren et al. 2011) in Scandinavia; actions, that lead to potentially unsustainable government culls in Norway (e.g. Kaltenborn et al. 1999; Sæther et al. 2005) and illegal poaching in Sweden (Persson et al. 2015), despite their regionally Vulnerable status (Landa 2007; Macdonald et al., Chapter 1, this volume). Compensation costs are high; nevertheless, the approach in Sweden, where compensation is based on 'risks', appears to be effective (Persson et al. 2015). In terms of practicable solutions, Hansen et al. (1997) report one observed instance where a large guarding dog was effective at driving a wolverine away from a flock of sheep in Norway; however Smith et al. (2000) caution that the risk that wolverines could turn upon and potentially kill guardian dogs, if cornered, are high.

Even less exclusively predatory species pose problems. Most states and provinces across the USA and Canada formally list raccoons as pests to agriculture subject to extensive control and counter-measures (Beasley and Rhodes 2008); a problem that is even less welcome in countries where they have been introduced (e.g. Ikeda et al. 2004; Macdonald et al., Chapter 1 , this volume). Raccoon predation on eggs can also be problematic for protected waterfowl (e.g. Crabtree and Wolfe, 1988), songbirds (Thompson and Burhans, 2003; Suraci et al. 2014), turtles and terrapins (Feinberg and Burke 2003), and even alligators (Fleming et al. 1976), all necessitating conservation interventions. In more urban settings, Newman and Byrne (Chapter 9, this volume) describe risks to people from 'raccoon roundworm' infection and from skunks and raccoons vectoring rabies. One might argue that fewer skunks and raccoons (two species for which populations are currently increasing, Table 7.1) might benefit the 
conservation of other valued and protected species, ecosystems, agriculture, and human health.

Seeking generalities, however, most other musteloid populations are declining, therefore lethal control (or population reduction) is often not an option and, in any case, can prove difficult to achieve. Moreover, for a number of reasons (including compensatory population effects, misidentification of the predators responsible for losses, and unintended community effects as a result of predator removal, discussed in Harrington et al., Chapter 7, this volume), it is often ineffective in redressing problems. Indeed, 'problems' are often more to do with human actions and human-modified environments than the behaviour of musteloids per se.

There are clearly situations worldwide that require management of musteloids (and a number of potential practical options are outlined in Harrington et al., Chapter 7, this volume), but-and again related to their diminutive size, the range of niches they occupy, and often their combination of tenacity with cunningmusteloids can pose small-scale, but incremental problems quite different, but similarly troublesome, to larger felids and canids. Indeed, part of this problem is that we do not tolerate wolves or lions around our cities and farmland. But specifically because musteloids tend to be less threatening, we often end up in protracted conflicts.

Having explored their ambassadorial potential, in the context of conservation marketing, and summarized, in terms of ecosystem services (as distinct from existence values), why people might be concerned if musteloids disappeared, the third and final section of this essay turns to the question of how their conservation might be considered in the geopolitical context of different priorities and infrastructural constraints between different nations. Dickman et al. (2015) accomplished this exercise for the Felidae, and here we repeat their analyses for the musteloids (as is more fully documented by Harrington et al. submitted).

\section{Identifying conservation priorities amongst the musteloids}

For each of 84 musteloids for which we had complete data, we first assessed their conservation priority relative to other musteloids. Following Dickman et al. (2015), the analysis considers priority species to be those that are (i) evolutionarily distinct (ED, as above), (ii) vulnerable (due to narrow or restricted habitat requirements), (iii) threatened (based on IUCN status), or (iv) not well protected by Protected Areas (PAs), and that have the potential to serve as umbrella species for other 'priority' musteloids (see Dickman et al. 2015 for further details).

The first four criteria are combined to produce a preliminary musteloid conservation priority ( $\mathrm{pMCP}$ ) score that describes the conservation priority of each species on its own merits; the pMCP score is then combined with the species' umbrella potential for other musteloids (quantified as the extent to which it overlaps the range of other musteloids, weighted by their priority or $\mathrm{pMCP}$ score) to produce a final musteloid conservation priority (MCP) score for each species that takes into account both the value or 'priority' of the focal species as well as its potential benefit to other musteloids (see Harrington et al. submitted).

Here, we use a modified version of the umbrella score (hereafter musteloid-umbrella) to the one used in the first section of this essay. For the ambassadorial analysis earlier, umbrella scores were calculated based on range overlap with all other terrestrial mammals (not just musteloids), weighted by the IUCN status and ED score (combined as the EDGE score) of species under the umbrella. Whereas the musteloid-umbrella score is weighted by their pMCP score, which includes IUCN status and ED score, but also vulnerability and protection in PAs.

Examining first the pMCP scores (without musteloid-umbrella scores) reveals that eight of the top $10 \mathrm{pMCP}$ scoring musteloids (those with the highest priority for conservation action) are, perhaps unsurprisingly, threatened species (although threat status is only one of the four criteria used to calculate this value). This includes the two critically endangered musteloids, the European mink (Mustela lutreola) and the pygmy raccoon (Table 30.1). The American badger (Taxidea taxus) and kinkajou (neither of which are threatened species) receive top $10 \mathrm{pMCP}$ scores on the basis of their very high ED scores. It is notable that we identified the kinkajou as only a moderately charismatic species earlier in this chapter, because of its Least Concern IUCN status and intermediate body size. Here we show that its high ED score contributes to its high pMCP score. The kinkajou's large range overlap with a diversity of other threatened mammals gave it a high umbrella score in our ambassadorial analyses and the same large range and overlap with priority musteloids contributes to it topping the musteloids when musteloid-umbrella value is added to the $\mathrm{pMCP}$ score to reach the final MCP score (below, Table 30.1).

Not all threatened species rank highly: the southern river otter, for example, is Endangered, but falls to 
Table 30.1 Musteloid species (and their IUCN threat status) ranked first by pMCP (preliminary musteloid conservation priority) and then by oIMCP (musteloid conservation priority) scores, showing the top 10 and bottom three ranking species (and those that move in and out of the 'top 10' when the musteloid-umbrella value is added to a species' pMCP score to obtain the final MCP score). See text for further details; methods and calculations are based on those in Dickman et al. (2015).

\begin{tabular}{|c|c|c|c|c|c|}
\hline Species & IUCN status & pMCP rank & MCP rank & & MCP rank \\
\hline Red panda & $E$ & 1 & $2(-1)$ & Kinkajou & 1 \\
\hline European mink & CE & 2 & $4(-2)$ & Red panda & 2 \\
\hline Pygmy or Cozumel raccoon & CE & 3 & $6(-3)$ & American badger & 3 \\
\hline American badger & LC & 4 & $3(+1)$ & European mink & 4 \\
\hline Kinkajou & LC & 5 & $1(+4)$ & Tayra & 5 \\
\hline Bornean ferret-badger & $E$ & 6 & $7(-1)$ & Pygmy or Cozumel raccoon & 6 \\
\hline Pygmy spotted skunk & V & 7 & $11(-4)$ & Bornean ferret-badger & 7 \\
\hline Sea otter & $E$ & 8 & $12(-4)$ & White-nosed coati & 8 \\
\hline Black-footed ferret & $E$ & 9 & $14(-5)$ & Long-tailed weasel & 9 \\
\hline Marine otter & $E$ & 10 & $16(-6)$ & American hog-nosed skunk & 10 \\
\hline$\ldots \ldots$ & & & & $\ldots \ldots$ & \\
\hline Tayra & LC & 29 & $5(+24)$ & Pygmy spotted skunk & 11 \\
\hline White-nosed coati & LC & 18 & $8(+10)$ & Sea otter & 12 \\
\hline Long-tailed weasel & LC & 47 & $9(+38)$ & Black-footed ferret & 14 \\
\hline American hog-nosed skunk & LC & 13 & $10(+3)$ & Marine otter & 16 \\
\hline$\cdots \cdots$ & & & & $\ldots \ldots$ & \\
\hline Japanese marten & LC & 82 & & Japanese marten & 82 \\
\hline Southern river otter & $E$ & 83 & & Southern river otter & 83 \\
\hline Palawan stink badger & $\mathrm{LC}$ & 84 & & Palawan stink badger & 84 \\
\hline
\end{tabular}

the bottom of the pMCP ranks partly because it has a low ED score but also because a large proportion of its range already occurs within PAs. Indeed, the otters generally (particularly species of the genera Lutra and Lontra) have low ED scores and so fall lower down the ranks.

The added benefit that each of the musteloids provides for other musteloids in terms of their musteloid-umbrella potential varies such that each species overlaps a total, across their range, of between 0 and 36 other musteloid species, with a mean of 13.1. Due to their restricted ranges, the black-footed ferret and pygmy raccoon (that occurs only on Cozumel Island), for example, exhibit no measurable overlap with other musteloids. The marine otter (Lontra felina), similarly, does not overlap any of the other (terrestrial) species due to its marine distribution, although the sea otter overlaps North American river otter (Lontra canadensis) and stoat (Mustela erminea) range in coastal areas.

Combining the number of species overlapped, the extent to which they are overlapped, and their pMCP scores revealed the Neotropical otter (Lontra longicaudis) as having the highest musteloid-umbrella score, closely followed by the long-tailed weasel (Mustela frenata), tayra, and kinkajou-the latter three thus all emerging as top 10 priority (MCP) species, although the long-tailed weasel and tayra otherwise score low in terms of priority on their own merits.

Notably, both the pygmy raccoon and the Bornean ferret badger (Melogale everetti; both poor umbrellas) remain within the top $10 \mathrm{MCPs}$ even when 'musteloidumbrellaness' is accounted for, and all are within the top 20 (presumably reflecting their high endangerment and vulnerability scores). Of course, the potential range of the black-footed ferret, if it were restored successfully to its historical range, is considerably more extensive than its current range that is restricted to a limited number of small reintroduction sites; on this basis, the black-footed ferret could potentially serve a significantly greater umbrella role for other musteloids if recovery efforts were successful-the same would be true of European mink (and any other species currently occupying an unnaturally restricted range), but the recovery of both species is currently hindered by 
disease and competitors, respectively (Biggins and Eads, Chapter 15, this volume; Maran et al., Chapter 17 , this volume). In the case of the black-footed ferret, its potential musteloid-umbrella role across the grasslands of the western United States is instead covered by the American badger (which has similar range and habitat associations and ranked 15th among musteloid umbrellas).

With the exception of the kinkajou, for which a high pMCP rank (see Table 30.1) is augmented further when considering musteloid-umbrella value - to make it the top-ranking $\mathrm{MCP}$-most high scoring $\mathrm{pMCP}$ species drop at least slightly in rank when considering umbrella-ness, such that, for example, the pygmy spotted skunk, sea otter, black-footed ferret, and marine otter drop out of the top 10-although all remain within the top 20 (as mentioned above for black-footed ferret and marine otter). Similarly, the red panda (Endangered and with high ED scores) concedes top $\mathrm{MCP}$ place to the kinkajou because the red panda is a poor musteloid-umbrella (ranked 66th) whereas the kinkajou is a good umbrella for other musteloids (ranked 4th). The white-nosed coati (Nasua narica) and the American hog-nosed skunk (Conepatus leuconotus) emerge as priority species because they have both reasonably high pMCP scores (see Table 30.1) and are reasonably good musteloid-umbrellas (ranked 10th and 20th, respectively).

Any ranking system is likely to perform better for some species than for others; however, whilst the details may reveal exceptions that require special treatment or consideration-for example, otters (that have fundamentally different habitat associations from other terrestrial musteloids, and many of which are threatened but do not rank highly in this analysis) and honey badgers (that perform poorly [ranked 39th] as an umbrella for musteloids because there are few musteloids in Africa, but are a very good umbrella for mammals in general) - the (imperfect) patterns allow us to consider simultaneously large numbers of species across global scales to reveal broad-scale generalities and enable us to make the first step in assessing which musteloids are priorities for immediate conservation action (although not suggesting that lower priority species do not merit attention). The implications for such prioritization are many and varied, including resource allocation decisions, for which funding bodies are increasingly sensitive to the risk of wasting money (Ferraro and Pattanayak 2006), strategies for reducing human-wildlife conflict, and gazetting of further Protected Areas.
Prioritizing species also allows us to assess which countries most urgently need investment in the conservation of musteloid populations. Further, we can assess whether the countries where musteloid conservation should be prioritized have a sound background infrastructure to support effective conservation. Of the 153 countries that have extant (or probably extant) musteloid populations, the average number of musteloids supported is 6.6 ( $8 \%$ of all musteloid species). Mexico supports the most musteloids (19, or $22 \%$ of musteloid species), USA (21\%), China (20\%), and France, Ecuador, and Colombia (19\%). Greenland, Sri Lanka, and a number of Arabian countries are home to only one musteloid (1.1\%).

Taking into account the conservation priority of species within a country, and the proportion of that species' range that the country contains (to calculate National Conservation Priority, or NCP, scores), the United States, Brazil, Mexico, Canada, and China emerge as the top five priority countries for musteloids. Other countries within the top 20 include Russia, Argentina, Chile, Indonesia, India, Peru, and Myanmar. The United Kingdom ranked a mere 83rd (out of 143 countries for which we had sufficient data for analysis), but France and Spain ranked considerably higher (16th and 21st, respectively), because they are home to the Critically Endangered European mink, in addition to the western European cohort of musteloids that occurs in the UK.

Following Dickman et al.'s (2015) approach of considering the outcomes that emerge from the intersection, at national levels, of priority scores for felids and national capacities to deliver in the face of infrastructural obstacles, we now do the same for musteloids. We consider how countries perform on two axes; their likelihood of conservation effectiveness (termed National Conservation Likelihood, NCL, scores) against the presence of musteloids and their MCP values within a country (encapsulated within the country NCP scores). First, this reveals 71 countries with higher than median NCP scores and thus high priority for musteloid conservation, 36 of which-including (amongst others) Canada, Spain, France, Japan, Thailand, Malaysia, Panama, Chile, Bolivia and Costa Rica-also have higher than median NCL scores, due to their robust geopolitical background and thus a potentially high likelihood of being effective (those countries in the upper right quadrant in Figure 30.3). Furthermore, these 36 countries collectively encompass 74 of the 84 musteloids included in the analysis, and cover on average $72 \%$ of those species' ranges. 


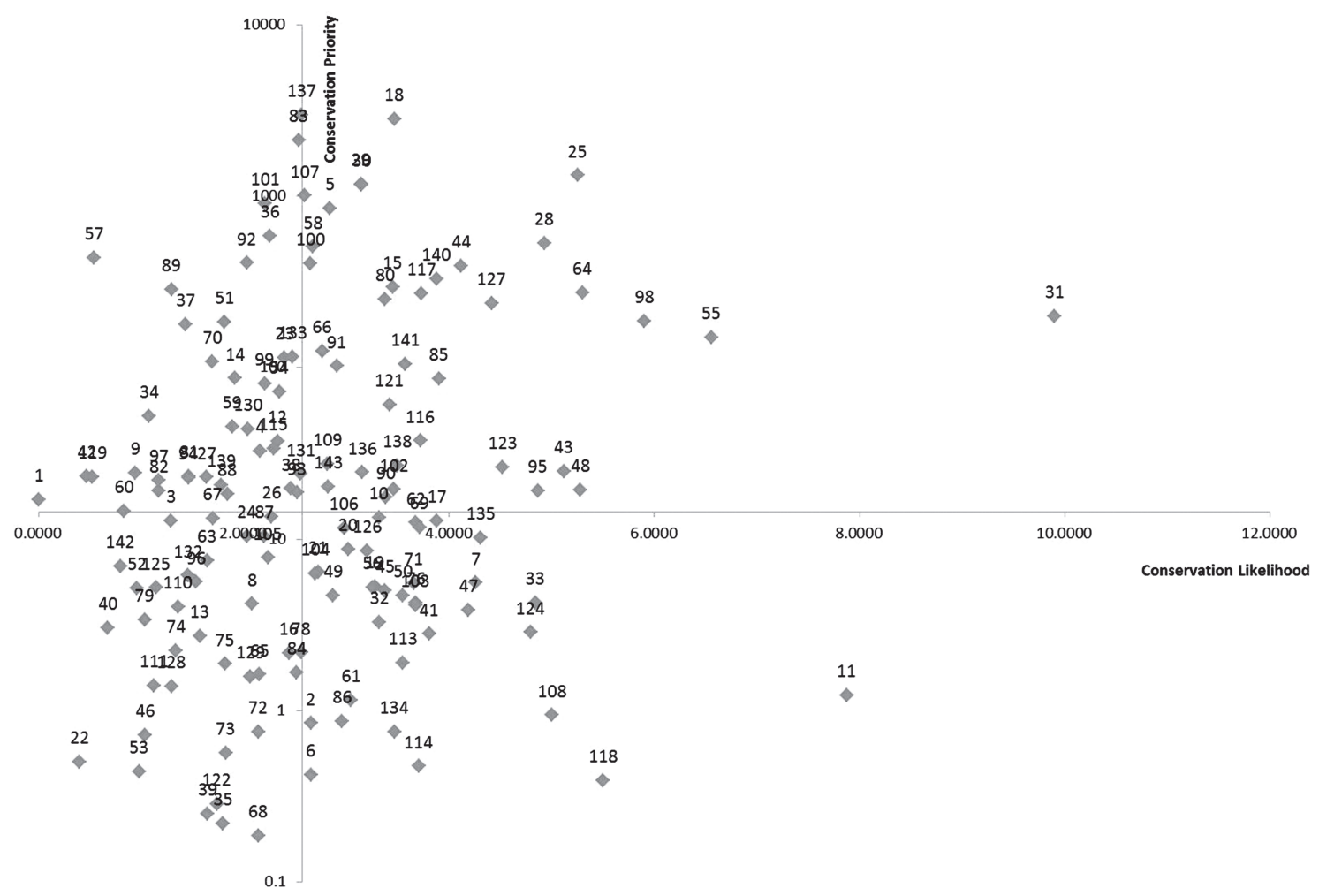

Figure 30.3 The distribution of countries according to their likelihood of conservation effectiveness (or 'conservation likelihood', based on National Conservation Likelihood, NCL, scores) and their conservation priority for musteloids (based on their National Conservation Priority, or NCP, scores). Axes are based at median values, and higher values mean higher likelihood of effectiveness or higher priority (i.e. those countries in the upper right quadrant are important for musteloids and are likely to effective, whereas those in the upper left quadrant are important for musteloids but less likely to be effective for various geopolitical reasons). NCL and NCP scores are calculated according to Dickman et al. (2015) for felids; further details and analysis in Harrington et al. (submitted). Country codes: 1, Afghanistan; 2, Albania; 3, Algeria; 4, Angola; 5, Argentina; 6, Armenia; 7, Austria; 8, Azerbaijan; 9, Bangladesh; 10, Belarus; 11, Belgium; 12, Belize; 13, Benin; 14, Bhutan; 15, Bolivia; 16, Bosnia and Herzegovina; 17, Botswana; 18, Brazil; 19, Brunei Darussalam; 20, Bulgaria; 21, Burkina Faso; 22, Burundi; 23, Cambodia; 24, Cameroon; 25, Canada; 26, Central African Republic; 27, Chad; 28, Chile; 29, China; 30, Colombia; 31, Costa Rica; 32, Croatia; 33, Czech Republic; 34, Congo, Dem. Rep.; 35, Djibouti; 36, Ecuador; 37, Egypt, Arab Rep.; 38, El Salvador; 39, Equatorial Guinea; 40, Eritrea; 41, Estonia; 42, Ethiopia; 43, Finland; 44, France; 45, Gabon; 46, Gambia, The; 47, Georgia; 48, Germany; 49, Ghana; 50, Greece; 51, Guatemala; 52, Guinea; 53, Guinea-Bissau; 54, Guyana; 55, Honduras; 56, Hungary; 57, India; 58, Indonesia; 59, Iran, Islamic Rep.; 60, Iraq; 61, Israel; 62, Italy; 63, Côte d'Ivoire (Ivory Coast); 64, Japan; 65, Jordan; 66, Kazakhstan; 67, Kenya; 68, Kuwait; 69, Kyrgyz Republic; 70, Lao PDR; 71, Latvia; 72, Lebanon; 73, Lesotho; 74, Liberia; 75, Libya; 76, Lithuania; 77, Luxembourg; 78, Macedonia, FYR; 79, Malawi; 80, Malaysia; 81, Mali; 82, Mauritania; 83, Mexico; 84, Moldova; 85, Mongolia; 86, Montenegro; 87, Morocc0; 88, Mozambique; 89, Myanmar; 90, Namibia; 91, Nepal; 92, Nicaragua; 93, Niger; 94, Nigeria; 95, Norway; 96, Oman; 97, Pakistan; 98, Panama; 99, Paraguay; 100, Peru; 101, Philippines; 102, Poland; 103, Portugal; 104, Serbia; 105, Congo, Rep.; 106, Romania; 107, Russian Federation; 108, Rwanda; 109, Saudi Arabia; 110, Senegal; 111, Sierra Leone; 112, Singapore; 113, Slovak Republic; 114, Slovenia; 115, South Africa; 116, Korea, Rep. (South Korea); 117, Spain; 118, Sri Lanka; 119, Sudan; 120, South Sudan; 121, Suriname; 122, Swaziland; 123, Sweden; 124, Switzerland; 125, Syrian Arab Republic; 126, Tajikistan; 127, Thailand; 128, Togo; 129, Tunisia; 130, Turkey; 131, Turkmenistan; 132, Uganda; 133, Ukraine; 134, United Arab Emirates; 135, United Kingdom; 136, Tanzania; 137, United States (not shown, occurs in the top left corner of the upper left quadrant); 138, Uruguay; 139, Uzbekistan; 140, Venezuela, RB; 141, VietNam; 142, Yemen, Rep.; 143, Zambia.

There was considerable variation in range coverage among species, from $3.7 \%$ to $100 \%$. However, (with the exception of the pygmy raccoon that has a very small restricted range) all of the top 10 priority species occur in high likelihood (high NCL scoring) countries, and, for 7 of those 'top 10', the vast majority of their range (77-100\%) falls into high likelihood countries. Two of the 'top 10 ' priority species-the American hog-nosed skunk and the white-nosed coati-occur predominantly (but not exclusively-64 and 70\% respectively) 
in low likelihood countries, but for both over half of their range occurs in Mexico which emerges as a low likelihood (low NCL-scoring) country but with a score only just below the median value (and thus on the cusp between high and low likelihood in this analysis, driven predominantly by the fact that it does not have any strictly Protected Areas, those classed as category I-IV by the IUCN). The pygmy raccoon occurs entirely on Cozumel Island (a Mexican island)-and, therefore, technically in a low likelihood country; however, although tourist development on the island is a serious threat to natural habitats there, there are initiatives underway to establish protected areas on the island and an environmental education programme to promote the conservation of endemic biota is already in place (Cuarón et al. 2016e). In short, most musteloids, and most of the highest priority musteloids, occur (and most of their range occurs) in relatively high likelihood countries. There are exceptions, and five musteloid species occur only in high priority, low likelihood countries (those that are important for musteloids generally but for various reasons are deemed to have a low likelihood of conservation effectiveness), but only one of these-the pygmy spotted skunk-is a high (ranked 11th in MCP score) priority species. The pygmy spotted skunk occurs entirely in Mexico.

Two countries that emerge as very high priority (but equally low likelihood-the centre of the upper left quadrant) for musteloids in general are India and Myanmar. These are the countries where conservation action is most needed to support and maintain populations of high priority musteloids, but where conservation may need to do more than the classical conservation actions of protecting habitat and reducing human wildlife conflict and/or illegal trade (the latter a particular issue in Myanmar, see Harrington et al., Chapter 7, this volume), but also address and consider corruption, poor economic forecast, and other factors such as high human population growth rate and increasing urban sprawl. For both India and Myanmar, governance is poor. India also suffers from very high human population density, extensive urban development, and a high density of human settlements. In contrast, although human population density and growth in Myanmar is low, which can relieve pressure on wildlife, poverty (indicated by below average GDP) is very high. The dire consequences for musteloids in both these countries can perhaps be illustrated by the apparent extinction of the hairynosed otter there (Aadrean et al. 2015) - however, both countries show some promise insofar as despite high human population density and high levels of poverty (respectively) a greater than average proportion of both countries is within Protected Areas.

\section{A perspective}

We are advocates of evidence-based policy, and thus that science (natural and social) is necessary to inform and underpin conservation in theory and in practice. However, it is also clear that science, while necessary, is insufficient to deliver conservation: ultimately conservation is about policy and its delivery, and while that policy should be based on evidence it will be formulated by societal and political desires (Macdonald 2013; Macdonald and Willis 2013; Macdonald 2016). Amongst the realpolitik of conservation we have illustrated in this essay three topics likely to affect the journey, for musteloids, from evidence to action: first, the extent to which they appeal to people, especially people from the engaged citizenry likely to put their money, or their votes, where their mouths are; second, the evidence that they are useful to people-a concept that has come to be known as ecosystem services (which are different to, although generally related to, ecosystem functions); third, the geopolitical realities that, amongst nation states, facilitate or constrain infrastructural delivery of conservation, and the likely return on investment. Our purpose in highlighting these three is not to imply they are the only important considerations (unsurprisingly, musteloids are not amongst the most promising candidates as poster-children for conservation, though some may be exceptionally significant rivets in Ehrlich's aeroplane of ecosystem function). Nevertheless, they do illustrate how far the tendrils of consideration extend when it comes to implementing the conservation of any group of animals, and in this case of members of the superfamily Musteloidea. Now that conservation approaches maturity as a topic, it is revealed to be as complicated and prone to gridlock as any other matter of societal choice and, ultimately, politics.

In passing, we have illustrated that extant mustelids dominate a wide diversity of carnivore niches, sufficiently distinct ecological trades that they cohabit without competitive exclusion, and resulting in a level of sympatry between diverse representatives of their taxon that is much greater than is typical for other carnivores. As a consequence, the conservation needs of the musteloids are much more varied, but just as challenging, as for other carnivore families. Musteloids require we protect almost every kind 
of habitat; boreal, temperate, and tropical forests, arid prairies, semi-deserts, and arctic tundra, rivers and wetlands, even tracts of ocean. Furthermore, their small size creates insidious management issues, where representatives are more urbanized than most other of their carnivore cousins, bar red foxes. The one asset these efforts have, of course, is that in attempting to conserve even those few top flagship musteloids, the benefits to other ecosystem members would be vast.

Ultimately, this raises the question why musteloid communities are so speciose; and by way of answer we finish where we began (in Chapter 6) - the grass roots of musteloid ecology. Broadly, excluded from the typical, dominant niche of cursorial predation by better adapted felids and canids they took to other and more diverse modes of life, leading to their different and diverse conservation needs and the wealth of conservation lessons they offer.

\section{Acknowledgments}

We are grateful to Amy Hinks for extracting the ambassadorial data from E. Macdonald et al. (submitted), and to her and Dawn Burnham, Amy Dickman, and Ewan Macdonald for discussion of our use of these data here. These same colleagues were also helpful in our geopolitical analysis based on Dickman et al. (2015). 